\title{
Flooded Paddy Ecosystem Harbors Methanol Oxidizing-Plant Growth Promoting Bacteria Belonging to Order Enterobacterales
}

\author{
Vijaya Rani ${ }^{1}$, Arti Bhatia ${ }^{2}$, Lata Nain $^{3}$ and Rajeev Kaushik ${ }^{3 *}$ \\ ${ }^{1}$ Division of Crop Protection, ICAR-IIVR, Varanasi- 221305, India \\ ${ }^{2}$ CESCRA, ICAR-IARI, Pusa Campus, New Delhi-110012, India \\ ${ }^{3}$ Division of Microbiology, ICAR-IARI, Pusa Campus, New Delhi-110012, India \\ *Corresponding author
}

\section{A B S T R A C T}

\begin{tabular}{|l|}
\hline Ke y w or d s \\
Methanol oxidizers, \\
Enterobacterales, \\
PGPR, $\mathrm{P}, \mathrm{K}, \mathrm{Zn}$ \\
solubilization, $\mathrm{N}_{2^{-}}$ \\
fixation, Indole \\
Acetic Acid
\end{tabular}

\section{Introduction}

Methanol concentration in environment plays an important role in atmospheric chemistry as low methanol emission is associated with low ozone concentration in the atmosphere (Galbally and Kirstine, 2002; Wennberg et al., 1998; Warneke et al., 1999). Approximately, $100 \mathrm{Tg} \mathrm{y}^{-1}$ of methanol emission is contributed by the plants
Methanol oxidizing organisms not only reduce atmospheric methanol concentration but also play a major role in enhancing methane oxidation through cross-feeding in synergism with methanotrophs. Possession of plant growth promoting (PGP) attributes in methanol oxidizing bacteria will prove to be a worthy candidate for developing novel biofertilizers having dual ability of plant growth promotion and reducing methane emission to a certain extent. We are reporting 11 plant growth promoting methanol oxidizing bacteria belonging to the genera Rahnella, Serratia, Enterobacter and Pantoea of order Enterobacterales isolated from phyllosphere, rhizosphere and non-rhizosphere of flooded paddies. Among 11 isolates, Rahnella aquatilisANRf177 showed significantly highest growth in AMS broth having $0.5 \%$ methanol as the sole C source. $R$. aquatilis MaAL105 produced significantly higher IAA and showed maximum solubilization of P and K. Pantoea sp. KAAr216 showed significantly maximum $\mathrm{N}_{2}$ fixation ability and solubilization of $\mathrm{Zn}$ salts. These efficient methanol oxidizing bacteria having PGP attributes can be evaluated under field conditions. 
methanol produced in flowering plants can either be stored in plant tissue, diffuse out through stomata or oxidized to formaldehyde by methanol oxidase. Microflora residing in rhizosphere, phyllosphere, non-rhizosphere or as endophytes of plants can utilize methanol and consume major proportion of it (Kolb, 2009). Apart from indigenous synthesis of methanol in plant system, paddy ecosystem differs greatly in terms of its chemical and biological environment.

Anaerobic condition in rice field created due to waterlogged situation leads to the growth and development of methanogenic archaea, which synthesizes methane (Komiya et al., 2015). Presence of microorganisms capable of oxidizing methane and methanol plays an important role in maintaining the global carbon balance and convert methane to methanol by virtue of its methane monooxygenase enzyme system (Pandey et al., 2014).

Methane derived-carbons particularly methanol from methanotrophs can be utilized by methanol oxidizers and enhance the methane utilization rate by cross-feeding (Qiu et al., 2009). Synergistic associations of methane and methanol oxidizers have been reported that favours utilization of methane due to removal of its end product methanol by the synergistic partner (Krause et al., 2017; Jeong et al., 2018).

Thus, it is important to focus research on identifying novel and efficient methanol oxidizing bacteria which can act synergistically with methanotrophs and reduce methane emission from flooded ecosystems such as paddies.

Further, certain plant growth promoting attributes in such isolates will prove worthy candidate for their inclusion in development of biofertilizers with dual ability of plant growth promotion and reducing the harmful effects of methane emission to a certain extent (Jhala et al., 2014). In present study, we analysed plant growth promoting traits in methanol oxidizing bacteria belonging to the order Enterobacterales. These isolates were previously isolated from different irrigated and rainfed flooded paddy ecosystem of India.

Till date, except for the genus Enterobacter (Madhaiyan et al., 2010; Lee et al., 2006), methanol oxidizing ability in other members of Enterobacterales such as Rahnella, Serratia and Pantoea has not yet been reported. Reports on members of Enterobacterales with plant growth promoting (PGP) traits such as $\mathrm{P}$ solubilization, IAA production and ACC deaminase activity are available (Mehnaz et al., 2010; Madhaiyan et al., 2010). The present study is focused on the characterization of plant growth promoting attributes of methanol oxidizing bacteria belonging to order Enterobacterales isolated from flooded paddy ecosystem.

\section{Materials and Methods}

Eleven methanol oxidizing bacterial isolates belonging to the genera Serratia, Rahnella, Pantoea and Enterobacter of order Enterobacterales were used in present study. The identification details and accession umber of the isolates is given in table 1. These isolates were previously isolated from phyllosphere, rhizosphere and nonrhizosphere samples collected from 4 diverse rice growing regions of India (Table 1).

Methanol oxidation ability of the 11 selected isolates was verified by culturing them in Ammonium mineral salt (AMS) broth having $0.5 \%$ methanol as the sole $\mathrm{C}$ source for $6 \mathrm{~d}$ at $30^{\circ} \mathrm{C}$ (Whittenbury et al., 1970) and quantifying growth by estimating total protein (Bradford, 1976). All the selected isolates were evaluated for plant growth-promoting 
(PGP) traits such as solubilization of P, K, Zn, fixation of atmospheric nitrogen and production of phytohormone indole acetic acid (IAA). The $\mathrm{P}$ solubilization was estimated qualitatively by formation of $\mathrm{P}$ solubilization halo zone around spot growth of the isolates on modified Pikovskaya (1948) agar having tri-calcium phosphate as $\mathrm{P}$ source (10.0 g glucose and $0.5 \mathrm{~g}$ yeast extract in Pikovskaya's medium was replaced with $0.5 \%$ methanol).

Phosphorus solubilization index [the ratio of the total diameter (colony + halo zone) to the colony diameter] was calculated. The $\mathrm{P}$ solubilization was quantified in positive isolates by inoculating $\left(10^{5}\right.$ cells $\mathrm{ml}^{-1}$ of inoculum) them in modified Pikovskaya's broth for $5 \mathrm{~d}$ at $30{ }^{\circ} \mathrm{C}$. Culture suspension was centrifuged at $5000 \mathrm{~g}$ for $15 \mathrm{~min}$ and the supernatant was used for estimating $P$ solubilization by ascorbic acid method (Olsen et al., 1954).

$\mathrm{K}$ solubilization activity of the bacterial isolates was estimated qualitatively by formation of $\mathrm{K}$ solubilization halo zone around spot growth of isolates after $5 \mathrm{~d}$ of incubation at $30^{\circ} \mathrm{C}$ on modified Alexandrov agar (5.0 g glucose in Alexandrov medium was replaced with $5.0 \mathrm{~mL}$ methanol) having potassium aluminum silicate as $\mathrm{K}$ source.

Similarly, Zn solubilization activity was determined by spot inoculating the isolates in 3 sets of modified AMS agar, each having different $\mathrm{Zn}$ salt $\mathrm{ZnO}, \mathrm{ZnCO}_{3}$, and $\mathrm{Zn}_{3}\left(\mathrm{PO}_{4}\right)_{2} @ 1 \mathrm{~g} \mathrm{~L}^{-1}$. The plates were incubated at $30{ }^{\circ} \mathrm{C}$ for 5-7 days and observed for the appearance of solubilization zone around the spot growth.

The $\mathrm{K}$ and $\mathrm{Zn}$ solubilization index was calculated by the formula: the ratio of the total diameter (colony + halo zone) to the colony diameter. The IAA production by the bacterial isolates was quantified by growing them for $3 \mathrm{~d}$ (log phase) at $30{ }^{\circ} \mathrm{C}$ in AMS broth supplemented with and without $100 \mu \mathrm{g}$ $\mathrm{L}^{-1}$ tryptophan (Doronina et al., 2001). The broth was centrifuged at $5000 \mathrm{~g}$ for $10 \mathrm{~min}$ after incubation and IAA was quantified in the supernatant as per the method described by Gordon and Weber (1951).

Nitrogen fixing ability of the isolates was determined through acetylene reduction assay (ARA) according to Hardy et al., (1968). The cultures were grown in 130-ml conical flask containing $55 \mathrm{ml}$ of $\mathrm{N}$ free AMS broth and sealed with airtight rubber septa for 6 days. $10 \%(\mathrm{v} / \mathrm{v})$ acetylene gas was injected by removing equal volume of air from the flask using a syringe and needle. The flasks were incubated for $24 \mathrm{~h}$ under continuous illumination at $30^{\circ} \mathrm{C}$. The ethylene concentration in head space was measured using a Gas Chromatograph with Flame ionization detector (FID). Commercially available standard ethylene was used for calibration. Calculations were done using the following formula.

ARA (nanomoles of ethylene per mg of protein per $h r$ ) $=\frac{C * P_{S} * A s * V}{P_{s t d} * A s t d * T * P}$

Where, $\mathrm{C}$ is concentration of ethylene in the standard in nanomole, Ps is peak area of sample, As is attenuation used for sample, Pstd is peak area of standard, Astd is attenuation used for standard, $\mathrm{T}$ is time of incubation in $\mathrm{h}, \mathrm{P}$ is protein content of bacterial growth, and $\mathrm{V}$ is volume of air space in the assay vial. The total protein content of bacterial cultures in the $\mathrm{N}$ free broth was done by the extraction of cells and estimated by Bradford's assay using Bovine Serum Albumin (BSA) as the standard.

Data was subjected to analysis of variance (ANOVA) using software SPSS ver. 10 and least significant difference (LSD) at $\mathrm{P} \leq 0.05$ among means compared using standard error. 


\section{Results and Discussion}

Isolation and identification details of methanol utilizing enterobacterales

Out of 11 methanol utilizing bacteria belonging to order Enterobacterales used in present study, 7 isolates (Pantoea sp. KAAr216, Rahnella aquatilis KAAr197, $R$. aquatilis AAL66, $R$. aquatilis MaAL105, Serratia sp. MaAAr216, S. odoriferaAAL50, and S. plymuthica ANL5) were isolated from the phyllosphere of rice plant. Three isolates (S. marcescens KAS146, Enterobacter sp. BAS18, and $R$. aquatilis BAS61) were isolated from non- rhizosphere and only 1 isolate $R$. aquatilis ANRf177 was obtained from the rhizosphere of 4 paddy growing regions. Among different paddy growing regions of India, maximum 4 isolates $(R$. aquatilis AAL66, $R$. aquatilis ANRf177, $S$. odorifera AAL50, and S. plymuthica ANL5) were obtained from medium land rainfed/ irrigated rice-rice monoculture of Aduthurai, Tamil Nadu, followed by 3 isolates (Pantoea sp. KAAr216, S. marcescens KAS146, and R.aquatilis KAAr197) from submerged low land rice-fish mixed farming paddy fields of Kochi, Kerala, and 2 each from upland irrigated rice-wheat cropping system of Gaya, Bihar (Enterobacter sp. BAS18, R. aquatilis BAS61) and upland irrigated rice-wheat cropping system (drought-prone) of Varanasi, Uttar Pradesh ( $R$. aquatilis MaAL105, Serratia sp. MaAAr216). All the 11 isolates were able to grow well by utilizing $0.5 \%$ methanol as the sole C source in AMS broth. The growth of the isolates was measured as total protein and it ranged from 41.00 to 65.24 protein $\mu \mathrm{gmL}^{-1}$ (Table 1). Maximum growth was observed by the isolate R.aquatilis ANRf177 (65.24 protein $\left.\mu \mathrm{gmL}^{-1}\right)$ isolated from rhizosphere of paddy from Aduthurai. It was significantly higher than all other isolates (Table 1). No clear pattern of growth on the basis of isolation site was observed. Repeated sub-culturing of isolates on AMS agar resulted in the loss of red and yellow pigmentation in the isolates of Serratia and Pantoea, respectively.

Phosphorous, potassium and zinc solubilization

Three isolates of R.aquatilis (BAS61, MaAL105, ANRf177) and 1 of each S.plymuthica ANL5, Enterobacter sp. BAS18 could show solubilization of phosphorus as indicated by $\mathrm{P}$ solubilization index (PSI) ranging from 1.15 to 1.73 (Table 2). Significantly higher PSI of $1.73 \pm 0.06$ was yielded by R.aquatilis MaAL105followed by R.aquatilis ANRf177 (1.25 \pm 0.04$)$ which was statistically at par with S.plymuthicaANL5 $(1.24 \pm 0.05)$ (Table 2). The P solubilization activity among 5 positive isolates was quantified and similar observation was recorded as far as maximum solubilization was concerned. R.aquatilisMaAL105 showed significantly higher $\mathrm{P}$ solubilization $\left(71.68 \pm 6.4 \mathrm{mg} \mathrm{L}^{-1}\right)$ than other 4 isolates. Though PSI of R.aquatilis ANRf177 and S.plymuthica ANL5 were statistically at par but upon quantification, S.plymuthicaANL5 showed significantly higher $\mathrm{P}$ solubilization $\left(45.92 \pm 4.29 \mathrm{mg} \mathrm{L}^{-1}\right)$ then R.aquatilis ANRf177 (35.01 $\left.\pm 4.49 \mathrm{mg} \mathrm{L}^{-1}\right)$.

The potassium solubilization activity of the isolates was quantified as $\mathrm{K}$ solubilization index (KSI). Only 3 isolates could show solubilization of K, i.e. R.aquatilis MaAL105, $R$. aquatilis KAAr197 and Enterobacter sp. BAS18.

R.aquatilis MaAL105 showed maximum KSI of $1.94 \pm 0.14$ in a plate assay and was statistically at par with the KSI of other 2 isolates, Enterobacter sp. BAS18 (1.85 \pm 0.09$)$ and $R$. aquatilis KAAr197 (1.66 \pm 0.09$)$ (Table 2). Three isolates, S.plymuthica ANL5, R.aquatilis MaAL105 and Pantoea sp. 
KAAr216, showed solubilization of all the three $\mathrm{Zn}$ salts viz. $\mathrm{ZnO}, \mathrm{ZnCO}_{3}$ and $\mathrm{ZnPO}_{4}$ (Table 2). Pantoea sp. KAAr216 solubilized $\mathrm{Zn}$ significantly higher than S.plymuthica ANL5 and R.aquatilis MaAL105 with Zn solubilization index (ZSI) of $3.80 \pm 0.04$, and $3.64 \pm 0.06$ on $\mathrm{Zn}$ salts, $\mathrm{ZnO}, \quad$ and $\mathrm{ZnPO}_{4}$, respectively. R.aquatilisMaAL105 solubilized $\mathrm{ZnCO}_{3}$ significantly higher than other isolates with ZSI of $3.98 \pm 0.08$ (Table 2). No clear pattern was observed among isolates about the preferred Zn sources.

\section{Nitrogen fixation}

Four isolates viz. S.plymuthica ANL5, R.aquatilis BAS61, R.aquatilis MaAL105 and Pantoea sp. KAAr216 possessed ability to fix atmospheric nitrogen. Significant variations in ARA activity was observed among all the 4 isolates and maximum ARA activity of 492.57 \pm 15.93 nmoles of $\mathrm{C}_{2} \mathrm{H}_{2}$ mg of protein ${ }^{-1}$ $\mathrm{h}^{-1}$ was shown by Pantoea sp. KAAr216 (Table 2). It was followed by S.plymuthica ANL5, R.aquatilis MaAL105 and R.aquatilis BAS61 with ARA activity of 402.23 \pm 2.30 , $320.56 \pm 15.67$, and $266.13 \pm 15.22$ nmoles of $\mathrm{C}_{2} \mathrm{H}_{2} \mathrm{mg}$ of protein ${ }^{-1} \mathrm{~h}^{-1}$, respectively (Table 2).

\section{IAA production}

Out of 11 only 3methanol utilizing bacteria viz. Enterobacter sp. BAS18, R.aquatilis MaAL105, and Pantoea sp. KAAr216 could show the ability to produce IAA in the presence and absence of tryptophan in the growth medium (Fig 1). In the absence of tryptophan R.aquatilis MaAL105 produced significantly higher IAA $(50.63 \pm 2.65 \mu \mathrm{g} \mathrm{mL}$ $\left.{ }^{1}\right)$ followed by Pantoea sp. KAAr216 $\left(42.51 \pm 3.89 \mu \mathrm{g} \mathrm{mL}^{-1}\right)$ andEnterobacter $\mathrm{sp}$. BAS18 (36.39 $\left.\pm 3.50 \mu \mathrm{g} \mathrm{mL}^{-1}\right) \quad($ Fig 1). In presence of tryptophan significant increase in the IAA production by the 3 isolates was observed. In like manner to trp ${ }^{-}$condition, R.aquatilis MaAL105 showed significantly higher IAA production $\left(72.31 \pm 6.98 \mu \mathrm{g} \mathrm{mL}^{-1}\right)$ in presence of tryptophan as compared to Enterobacter sp. BAS18 and Pantoea sp. KAAr216. In contrast to trp ${ }^{-}$condition the Enterobacter sp. BAS18 showed significantly higher production of IAA $\left(55.88 \pm 3.71 \mu \mathrm{g} \mathrm{mL}{ }^{-}\right.$ $\left.{ }^{1}\right)$ than Pantoea sp. KAAr216 (50.02 $\pm 1.37 \mu \mathrm{g}$ $\mathrm{mL}^{-1}$ ) in presence of tryptophan in the growth medium (Fig 1).

Atmospheric methanol contributes to pool of reactive volatile organic compounds which triggers the formation of trophopsheric ozone, an important greenhouse gas, in the atmosphere (Finlayson-Pitts and Pitts Jr., 1993). The major source of atmospheric methanol is the terrestrial ecosystem and methanol oxidizing microorganisms play an important role in regulating its concentration (Kolb, 2009). The synergistic association between methanotrophic and methanol oxidizing microorganisms at the soil water interface is known to enhance the methane utilization rate in wetlands (Qiu et al., 2009). Methanol utilizing plant associated bacteria are also known to possess many plant growth promoting attributes (Ahlawat et al., 2018) and hence, can be used for developing bioinoculants for crops grown in flooded ecosystem such as paddy. The dual ability, plant growth promotion and lowering the methane emission, of such inoculants will be of great importance in mitigating harmful effects of greenhouse gas especially methane. Previously, we isolated large number of methanol oxidizing bacteria from phyllosphere, rhizosphere and nonrhizosphere regions of different flooded paddy ecosystem and 11 of these isolates belonged to order Enterobacterales (Table 1) and were identified as Enterobacter sp. BAS18, R.aquatilis BAS61, $R$. aquatilis AAL66, $R$. aquatilis MaAL105, $R$. aquatilis ANRf177, R.aquatilis KAAr197, Serratia sp. 
MaAAr216, S. plymuthica ANL5, $S$. odorifera AAL50, S. marcescens KAS146, Pantoea sp. KAAr216. Out of 11 isolates, 7 were isolated from phyllosphere of paddy. The abundance of methanol utilizing methylotrophs on above ground plant parts including leaves and aerenchymatous tissue as compared to soil in paddy ecosystem was also reported by Jain et al., (2004). Among sampling locations, 7 isolates were isolated from lowland paddy fields of Aduthurai and Kochi. It could be due to higher concentration of methane produced due to submerged conditions and subsequently higher production of methanol.

All the 11 isolates were verified once again for their ability to grow and utilize methanol as the only $\mathrm{C}$ source and R.aquatilisANRf177 showed significantly higher growth (65.24 protein $\mu \mathrm{gmL}^{-1}$ )than other isolates. The ability to utilize methanol as the sole carbon source by the bacteria belonging to genera Rahnella, Serratiaand Pantoea is not yet reported. However, Enterobacter with methanol oxidizing ability was earlier isolated from rice and groundnut (Lee et al., 2006; Hardoim et al., 2013; Madhaiyan et al., 2010). The presence of mxaF gene encoding methanol dehydrogenase enzyme catalyzing conversion of methanol to formaldehyde in Enterobacter oryzendophyticus was confirmed by Hardoim et al., (2013).

The members of Enterobacterales are well known for their PGPR traits such as $\mathrm{P}$ solubilization, IAA production and ACC deaminase activity in R.aquatilis (Mehnaz et al., 2010), $\mathrm{N}_{2}$ fixation in Enterobacter arachidis (Madhaiyan et al., 2010). Five of the isolates in present study showed $\mathrm{P}$ solubilization ability. Rahnella aquatilis MaAL105 showed significantly higher $\mathrm{P}$ solubilization than other isolates with PSI of 1.73 \pm 0.06 . Besides Rahnella, S.plymuthica ANL5 and Enterobacter BAS18 also solubilized P and yielded PSI of $1.24 \pm 0.05$ and 1.19 \pm 0.01 , respectively. Positive effect of inoculating phosphate solubilizing bacteria R.aquatillis, Enterobacter sp., Pseudomonas fluorescens and $P$. putida on rice plant growth and yield were also reported earlier (Bakhshandeh et al., 2015). Isolate Enterobacter BAS18, R.aquatilis MaAL105 and R.aquatilis KAAr197 solubilized K with a solubilization index of $1.85 \pm 0.09,1.94 \pm 0.14$ and $1.66 \pm 0.09$, respectively. Bakhshandehand co-workers (2017) in a study co-inoculated phosphate and potash solubilizing cultures of Pantoea ananatis, R.aquatilis and Enterobacter sp. in rice crop and obtained positive effect of inoculation on plant height, stem diameter, root length, leaf area and biomass dry weight. They also observed significant increase of $\mathrm{K}$ uptake in leaves, root and stem of seedling upon inoculation with $\mathrm{K}$ solubilizing bacteria. The solubilization of three $\mathrm{Zn}$ slats, $\mathrm{ZnO}, \mathrm{ZnCO}_{3}$ and $\mathrm{ZnPO}_{4}$ was observed in S.plymuthica ANL5, R.aquatilis MaAL105 and Pantoea sp. KAAr216 (Table 2). The ability to solubilize zinc in members of these genera has also been reported earlier by various workers (Othman et al., 2017; Kamran et al., 2017). Positive effect of inoculating zinc solubilizing cultures of genera Pantoea, Enterobacter, Pseudomonas and Rhizobium on plant growth and yield parameters in wheat plant was observed previously (Kamran et al., 2017). Four of the bacteria, S. plymuthica ANL5, $R$. aquatilis BAS6, R. aquatilis MaAL105, and Pantoea sp. KAAr216 showed the ability to fix atmospheric N (Table2).

R.aquatilis was recognized long time ago as $\mathrm{N}_{2}$ - fixing enteric bacteria isolated from rhizosphere of wheat and maize (Berge et al., 1990). Positive effect of inoculating $\mathrm{N}_{2-}$ fixing Pantoea agglomerans strain on rice plant growth and photosynthate allocation was also reported previously (Feng et al., 2006). Advanced study on insitu $\mathrm{N}_{2}$ fixation by Serratia sp. in rice plant using molecular tools has been studied in details (Sandhiya et 
al., 2005; Gyaneshwar et al., 2001). Indole acetic acid (IAA) is an important plant hormone and plays important role in stem elongation and lateral root proliferation (Egamberdieva 2012). Microorganisms can produce this hormone and exert positive effect on plant growth. Three isolates viz. Enterobacter BAS18, $R$. aquatilisMaAL105 and Pantoea sp. KAAr216 showed the ability of IAA production, in presence and absence of tryptophan. IAA production in the Enterobacter sp isolated from rice phyllosphere was also reported earlier (Nutaratat et al., 2017). The effect of $\mathrm{N}_{2}$ fixing and IAA, abscisic acid, gibberellic acid and cytokinin producing Pantoea agglomerans strain on rice plant growth was also investigated earlier (Feng et al., 2006).
Khan and Doty (2009) studied the positive effect of IAA producing R.aquatilis strain on root growth induction in hybrid poplar plant. Based on the results, it can be concluded that that methanol utilizing bacteria belonging to order Enterobacterales can be of economic importance in agriculture and R.aquatilis MaAL105which showed promising results holds tremendous potential as a probable candidate for developing novel biofertilizer for paddy having dual property of plant growth promotion and methanol utilization. Hence, potential of R.aquatilis MaAL105 should be evaluated under field condition to promote growth of the plant and reduction in the emission of methane by assisting its utilization by methanotrophs through crossfeeding.

Table.1 Identification details, isolation sites of methanol utilizing isolates belonging to the order Enterobacterales and their growth measured as total protein in AMS broth with $0.5 \%$ methanol as sole $\mathrm{C}$ source

\begin{tabular}{|c|c|c|c|c|c|c|}
\hline & Identified Genera & $\begin{array}{c}\text { Accession } \\
\text { Number }\end{array}$ & $\begin{array}{c}\% \\
\text { Similarity }\end{array}$ & $\begin{array}{c}\text { Protein } \\
\left(\mu \mathrm{g} \mathrm{mL} L^{-1}\right)^{1}\end{array}$ & $\begin{array}{c}\text { Isolation } \\
\text { site }\end{array}$ & Habitat \\
\hline 1. & Serratia plymuthica ANL5 & MG846078 & 99.78 & $50.20^{\mathrm{ef}}$ & Aduthurai $^{2}$ & Phyllosphere \\
\hline 2. & Enterobacter sp. BAS18 & MG846083 & 99.93 & $56.49^{\text {cd }}$ & Gaya $^{3}$ & Non rhizosphere \\
\hline 3. & Serratia odorifera AAL50 & KY810630 & 99.93 & $49.00^{f}$ & Aduthurai & Phyllosphere \\
\hline 4. & Rahnella aquatilis BAS61 & KY810633 & 100.00 & $57.97^{\text {cd }}$ & Gaya & Non Rhizosphere \\
\hline 5. & Rahnella aquatilis AAL66 & KY810634 & 99.93 & $53.75^{\text {de }}$ & Aduthurai & Phyllosphere \\
\hline 6. & Rahnella aquatilis MaAL10 & KY810649 & 100.00 & $65.38^{\mathrm{a}}$ & Varanasi $^{4}$ & Phyllosphere \\
\hline 7. & Serratia marcescens KAS146 & MG846106 & 99.77 & $41.00^{\mathrm{g}}$ & Kochi $^{5}$ & Non rhizosphere \\
\hline 8. & Rahnella aquatilis ANRf177 & MG846110 & 100.00 & $65.24^{\mathrm{a}}$ & Aduthurai & Rhizosphere \\
\hline 9. & Rahnella aquatilisKAAr197 & KY810674 & 99.93 & $59.15^{\mathrm{bc}}$ & Kochi & Phyllosphere \\
\hline 10. & Pantoea sp. KAAr216 & MG846111 & 99.86 & $55.00^{\mathrm{cd}}$ & Kochi & Phyllosphere \\
\hline 11. & Serratia sp. MaAAr216 & MG846112 & 100.00 & $63.73^{\mathrm{ab}}$ & Varanasi & Phyllosphere \\
\hline
\end{tabular}

${ }^{1} \operatorname{LSD}(\mathrm{p} \geq 0.05$ ) for protein is 4.59

${ }^{2}$ Medium land rainfed and irrigated rice-rice monoculture, Aduthurai, Tamil Nadu; ${ }^{3}$ Upland irrigated rice-wheat cropping system, Gaya, Bihar; ${ }^{4}$ Upland irrigated rice-wheat cropping system (drought-prone), Varanasi, Uttar Pradesh; ${ }^{5}$ Submerged lowland rice-fish mixed farming, Kochi, Kerala 
Table.2 Nitrogen fixation, $\mathrm{P}, \mathrm{K}$ and Zn solubilization activity of the methanol utilizing bacteria of order Enterobacterales

\begin{tabular}{|c|c|c|c|c|c|c|c|}
\hline \multirow[t]{2}{*}{ Isolates } & \multirow{2}{*}{$\begin{array}{c}\mathbf{P} \\
\text { solubilization } \\
\text { index }\end{array}$} & \multirow{2}{*}{$\begin{array}{c}\mathbf{P} \\
\text { Solubilization } \\
\left(\mathrm{mg} \mathrm{L}^{-1}\right)\end{array}$} & \multirow{2}{*}{$\begin{array}{c}\text { K } \\
\text { solubilization } \\
\text { index }\end{array}$} & \multicolumn{3}{|c|}{ Znsolubilization index } & \multirow{2}{*}{$\begin{array}{c}\mathrm{N}_{2} \text { - fixation } \\
\text { (nmoles of } \mathrm{C}_{2} \mathrm{H}_{2} \mathrm{mg} \text { of } \\
\text { protein }{ }^{-1} h^{-1} \text { ) }\end{array}$} \\
\hline & & & & $\mathrm{ZnO}$ & $\mathrm{ZnCO}_{3}$ & $\mathrm{ZnPO}_{4}$ & \\
\hline S. plymuthica ANL5 & $1.24 \pm 0.05$ & $45.92 \pm 4.29$ & ND & $3.23 \pm 0.11$ & $3.22 \pm 0.12$ & $3.14 \pm 0.06$ & $402.23 \pm 2.30$ \\
\hline Enterobacter sp. BAS18 & $1.19 \pm 0.01$ & $27.89 \pm 2.56$ & $1.85 \pm 0.09$ & ND & ND & ND & ND \\
\hline S. odorifera AAL50 & $\mathrm{ND}^{1}$ & ND & ND & ND & ND & ND & ND \\
\hline R. aquatilis BAS61 & $1.15 \pm .04$ & $22.09 \pm 3.30$ & ND & ND & ND & ND & $266.13 \pm 15.22$ \\
\hline R. aquatilis AAL66 & ND & ND & ND & ND & ND & ND & ND \\
\hline R. aquatilis MaAL105 & $1.73 \pm 0.06$ & $71.68 \pm 6.4$ & $1.94 \pm 0.14$ & $3.55 \pm 0.20$ & $3.98 \pm 0.07$ & $3.40 \pm 0.23$ & $320.56 \pm 15.67$ \\
\hline S. marcescens KAS146 & ND & ND & ND & ND & ND & ND & ND \\
\hline R. aquatilis ANRf177 & $1.25 \pm 0.04$ & $35.01 \pm 4.49$ & ND & ND & ND & ND & ND \\
\hline R. aquatilis KAAr197 & ND & ND & $1.66 \pm 0.09$ & ND & ND & ND & ND \\
\hline Pantoea sp. KAAr216 & ND & ND & ND & $3.80 \pm 0.04$ & $3.73 \pm 0.12$ & $3.64 \pm 0.06$ & $492.57 \pm 15.93$ \\
\hline Serratia sp. MaAAr216 & ND & ND & ND & ND & ND & ND & ND \\
\hline $\operatorname{LSD}_{(p \leq 0.05)}$ & 0.08 & 8.02 & NS & 0.265 & 0.21 & 0.285 & 31.83 \\
\hline
\end{tabular}

${ }^{1}$ ND: Not detected 


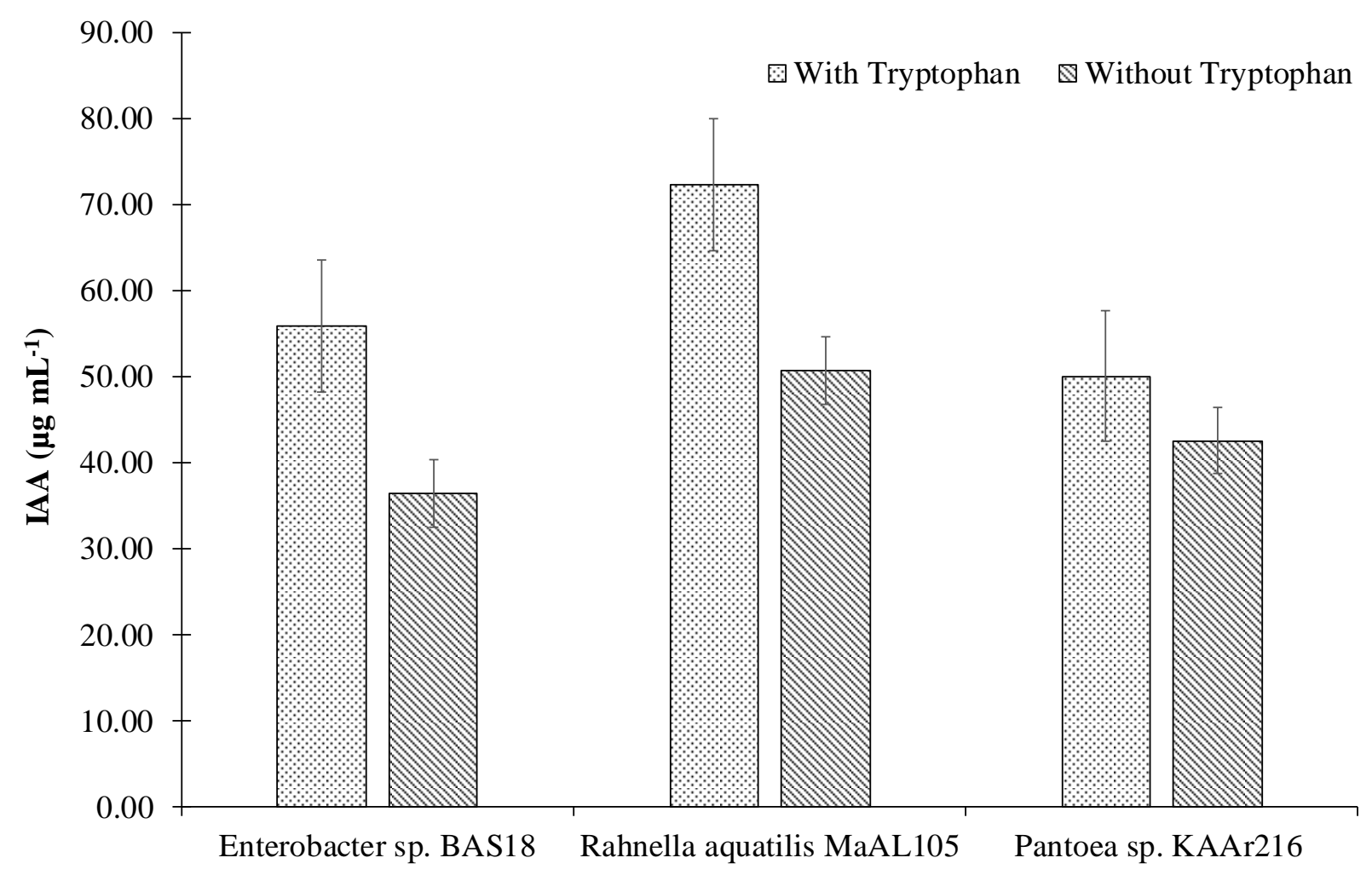

\section{Isolates}

Figure.1 IAA production by different methanol utilizing bacterial isolates grown in absence and presence of tryptophan

Eleven methanol utilizing bacteria belonging to order Enterobacterales and genera Rahnella, Serratia, Enterobacter and Pantoea were evaluated for their PGPR traits. Multiple PGPR traits such as $\mathrm{P}, \mathrm{K}, \mathrm{Zn}$ solubilization, $\mathrm{N}_{2}$ fixation and IAA production were detected in S.plymuthica ANL5,Enterobacter sp. BAS18, R.aquatilis BAS61, R.aquatilis MaAL105, R.aquatilis ANRf177 and Pantoea sp. MaAAr216. The R.aquatilisMaAL105 possessed all the traits studied and holds tremendous potential for developing it as a novel biofertilizer for flooded paddies. However, before that its potential should be evaluated under field condition to promote growth of the plant and reduction in the emission of methane by assisting its utilization by methanotrophs through crossfeeding.

\section{Acknowledgments}

Authors acknowledge the Division of Microbiology, ICAR-Indian Agricultural Research Institute (IARI), New Delhi and ICAR-Network project on National Initiative on Climate Resilient Agriculture, Centre for Environmental Science and Climate Resilient Agriculture, ICAR-IARI, New Delhi for providing facilities and funds. The author is also thankful to the University Grants Commission, Government of India for providing Senior Research Fellowship to the first author during her Ph.D. program.

\section{References}

Ahlawat, U., Sansanwal, R., Batra, P., Wati, L. 2018. Isolation and Characterization 
of Methanol Utilizing Microorganisms from Leguminous Crops. International Journal of Current Microbiology and Applied Sciences. 7(2): 1674-1691.

Bakhshandeh, E., Pirdashti, H., Lendeh, K. S. 2017. Phosphate and potassiumsolubilizing bacteria effect on the growth of rice. Ecological Engineering. 103: 164-169.

Bakhshandeh, E., Rahimian, H., Pirdashti, H., Nematzadeh, G. A. 2015. Evaluation of phosphate-solubilizing bacteria on the growth and grain yield of rice (Oryza sativa L.) cropped in northern Iran. Journal of Applied Microbiology 119: 1371-1382.

Berge, O., Heulin, T., Achouak, W. 1990. Rahnella aquatilis, a nitrogen-fixing enteric bacterium associated with the rhizosphere of wheat and maize. Canadian Journal of Microbiology. 37(3): 195-203.

Bradford, M. M. 1976. A rapid and sensitive method for the quantification of microgram quantities of protein utilising the principle of protein-dye binding. Anal. Biochem. 72: 248-254.

Doronina, N. V., Ivanova, E. G., Trotsenko, Y. A. 2001. New Evidence for the Ability of Methylobacteria and Methanotrophs to Synthesize Auxins. Microbiology. 71(1): 116-118.

Egamberdieva, D. 2012. Indole-acetic acid production by root associated bacteria and its role in plant growth and development. In Auxins: Structure, Biosynthesis and Functions; Keller, A.H., Fallon, M.D., Eds.; Nova Science Publishers Inc.: Hauppauge, NY, USA, pp. 103-122.

Fall, R. and Benson, A. A. 1996. Leaf methanol - the simplest natural product from plants. Trends in Plant Science. 1: 296-301.

Feng, Y., Shen, D., Song, W. 2006. Rice endophyte Pantoea agglomerans YS19 promotes host plant growth and affects allocations of host photosynthates. Journal of Applied Microbiology. 100(5): 938-945.

Finlayson-Pitts, B. J. and Pitts, J. N. 1993. Atmospheric Chemistry of Tropospheric Ozone Formation: Scientific and Regulatory Implications. Air \& Waste. 43(8): 1091-1100.

Frenkel, C., Peters, J. S., Tieman, D. M., Tiznado, M. E., and Handa, A. K., 1998. Pectin methylesterase regulates methanol and ethanol accumulation in ripening tomato (Lycopersicon esculentum) fruit. J. Biol. Chem. 273: 4293-4295.

Galbally, I. E. and Kirstine, W. 2002. The production of methanol by flowering plants and the global cycle of methanol. J Atmos Chem. 43: 195-229.

Gordon, S. A. and Weber, R. P. 1951. Colorimetric estimation of indole acetic acid. Plant Physiol. 26(1): 192-195.

Gyaneshwar, P., James, E. K., Mathan, N., Reddy, P. M., Reinhold-Hurek, B., Ladha, J. K. 2001. Endophytic colonization of rice by a diazotrophic strain of Serratia marcescens. J Bacteriol. 183(8): 2634-2645.

Hardoim, P. R., Nazir, R., Sessitsch, A., Elhottova, D., Korenblum, E. Overbeek, L. S., Elsas, J. D. 2013. The new species Enterobacter oryziphilus sp. nov. and Enterobacter oryzendophyticus sp. nov. are key inhabitants of the endosphere of rice. BMC Microbiology. 13:164.

Hardy, R.W.F., Holsten, R. D., Jackson, E. K., Burns, R.C. 1968. The acetylene ethylene assay for $\mathrm{N}_{2}$ fixation. Laboratory and field evaluation. Plant Physiol. 43: 1185-1207.

Jain, N., Pathak, H., Mitra, S., Bhatia, A. 2004. Emission of methane from rice fields- A review. Journal of scientific and industrial research. 63: 101- 115. 
Jeong, S. Y., Kim, T. G. 2018. Development of a novel methanotrophic process with the helper micro- organism Hyphomicrobium sp. NM 3. Journal of applied microbiology. 126(2): 534- 544.

Jhala, Y. K., Vyas, R. V., Sheat, H. N., Patel, H. K., Patel, K. T. 2014. Isolation and characterization of methane utilizing bacteria from wetland paddy ecosystem. World J MicrobiolBiotechnol. 30: 1845-1860.

Kamran, S., Shahid, I., Baig, D. N., Rizwan, M., Malik, K. A., Mehnaz, S. 2017. Contribution of Zinc Solubilizing Bacteria in Growth Promotion and Zinc Content of Wheat. Front Microbiol. 8: 2593.

Khan, Z. and Doty, S. 2009. Characterization of bacterial endophytes of sweet potato plants. Plant and Soil. 322: 197-207.

Kolb, S. 2009. Aerobic methanol-oxidizing Bacteria in soil. FEMS Microbiol Lett. 300: $1-10$.

Komiya, S., Noborio, K., Katano, K., Pakoktom, T., Siangliw, M., Toojinda, T. 2015. Contribution of ebullition to methane and carbon dioxide emission from water between plant rows in a tropical rice paddy field. International Scholarly Research Notices. 1-8.

Krause, S. M. B., Johnson, T., Karunaratne, S. Y., Fu, Y., Beck, D. A. C., Chistoserdova, L., Lidstrom M. E. 2017. Lanthanide-dependent cross feeding of methane-derived carbon is linked by microbial community interactions. Proceedings of the National Academy of Sciences. 114: 358- 363.

Lee, H., Madhaiyan, M., Kim, C., Choi, S., Chung, K., Min, S. T. 2006. Physiological enhancement of early growth of rice seedlings (Oryza sativa L.) by production of phytohormone of $\mathrm{N}_{2}$-fixing methylotrophic isolates. BiolFertil Soils. 42: 402-408.
Madhaiyan, M., Poonguzhali, S., Lee, J. S., Saravanan, V. S., Lee, K. C., Santhanakrishnan, $\quad$ P. 2010. Enterobacterar achidis sp. nov., a plantgrowth-promoting diazotrophic bacterium isolated from rhizosphere soil of groundnut. Int J SystEvolMicrobiol. 60: 1559-1564.

Mehnaz S., Baig, D.N., Lazarovits, G. 2010. Genetic and phenotypic diversity of plant growth promoting rhizobacteria isolated from sugarcane plants growing in Pakistan. J. Microbiol. Biotechnol. 20: 1614-1623.

Nutaratat, P., Monprasit, A., Srisuk, N. 2017. High-yield production of indole-3acetic acid by Enterobacter sp. DMKURP206, a rice phyllosphere bacterium that possesses plant growth-promoting traits. 3 Biotech. 7(5): 305.

Olsen, S. R., and Sommers, L. E. 1982. Phosphorus. In A. L. page et al., (ed) Methods of soil analisis, 2nd ed. Agronomy. 9: 403-430.

Othman, N. M. I., Othman, R., Saud, H. M., Wahab, P. E. M. 2017. Effects of root colonization by zinc-solubilizing bacteria on rice plant (Oryza sativa MR219) growth. Agriculture and Natural Resources. 51(6): 532-537.

Pandey, V. C., Singh, J. S., Singh, D. P., Singh, R. P. 2014. Methanotrophs: promising bacteria for environmental remediation. Int. J. Environ. Sci. Technol. 11:241-250.

Pikovskaya, R. I. 1948. Mobilization of phosphorus in soil in connection with the vital activity of some microbial species. Mikrobiologiya. 17: 362-370.

Qiu, Q., Conrad, R., Lu, Y. 2009. Cross feeding of methane carbon among bacteria on rice roots revealed by DNA -stable isotope probing. Environ Microbiol Rep. 1: 355 -361.

Sandhiya, G. S., Sugitha, T. C., Balachandar, D., Kumar, K. 2005. Endophytic 
colonization and in planta nitrogen fixation by a diazotrophic Serratia sp. in rice. Indian J Exp Biol. 43(9): 802- 807.

Warneke, C., Karl, T., Judmaier, H., Hansel, A., Jordan, A., Lindinger, W., Crutzen, P. J. 1999 Acetone, methanol, and other partially oxidized volatile organic emissions from dead plant matter by a biological processes: significance for atmospheric HOx chemistry. Global
Biogeochem Cy. 13: 9-17.

Wennberg, P. O., Hanisco, T. F., Jaegle, L. et al., 1998. Hydrogen radicals, nitrogen radicals, and the production of $\mathrm{O}_{3}$ in the upper troposphere. Science. 279: 49-53. Whittenbury, R., Phillips, K. C., Wilkinson, J. F. 1970. Enrichment, Isolation and Some Properties of Methane-Utilizing Bacteria. Journal of General Microbiology. 61: 205-218.

\section{How to cite this article:}

Vijaya Rani, Arti Bhatia, Lata Nain and Rajeev Kaushik. 2020. Flooded Paddy Ecosystem Harbors Methanol Oxidizing-Plant Growth Promoting Bacteria Belonging to Order Enterobacterales. Int.J.Curr.Microbiol.App.Sci. 9(07): 685-696.

doi: https://doi.org/10.20546/ijcmas.2020.907.079 